\title{
Molecular Marker Assisted Confirmation of Hybridity in Indian mustard (Brassica juncea L.)
}

\author{
Manmohan Sharma, Dechen Dolkar, R.K. Salgotra, Deepika Sharma, \\ Punya*, Amrinder Singh and S.K. Gupta
}

\author{
School of Biotechnology, Sher-e-Kashmir University of Agricultural Sciences \& Technology \\ of Jammu ( $J \& K)$, India \\ *Corresponding author
}

\section{A B S T R A C T}

\section{Keywords}

Brassica juncea $\mathrm{L}$.,

Hybridity, SSR markers, Polymorphism, Alleles

Article Info

Accepted:

08 August 2018

Available Online:

10 September 2018
The present study was undertaken to confirm the hybridity of Brassica juncea $\mathrm{L} . \mathrm{F}_{1}$ plants based on the amplification pattern of SSR markers. The complementary banding pattern of the male and female parents helped to confirm the genuineness of $F_{1}$ plants developed. The seeds of two genotypes of Brassica juncea, RSPR-01 used as female parent and DonskajaIV used as male parent were raised in pots under field conditions and crossed to develop $\mathrm{F}_{1}$ seeds. Out of 20 random SSR primers used for the screening of parental genotypes for polymorphism, 5 primers were found polymorphic. Based on the complementary banding patterns between the hybrid plants and parents, the polymorphic SSR markers BR_A04_9627743 and BR_A01_13393871 were identified as the specific markers which enable to distinguish and identify hybrid form their parental lines. The expression of both the parental alleles in six out of the seven plants confirmed their true hybrid nature.

\section{Introduction}

Brassica juncea L. $(2 \mathrm{n}=36)$ is a selfpollinated natural allopolyploid (AABB) evolved from interspecific hybridization between diploid B. rapa (AA, $\mathrm{n}=10$ ) and B. nigra $(\mathrm{BB}, \mathrm{n}=8)$. It is cultivated as an oilseed, condiment as well as a vegetable in some parts of the world. It occupies major area in India contributing more than 80 percent of the total rapeseed mustard production. In order to increase the efficiency of a hybrid breeding to achieve a breakthrough in the productivity of Indian mustard, careful evaluation of hybrid combinations between suitable parental lines is important.
Conventional screening methods have limited applicability to confirm whether a crossed/ $\mathrm{F}_{1}$ plant is actually a hybrid or selfed by chance self-fertilization. Therefore, selection of promising hybrids based on phenotypic observations is many times doubtful due to morphological similarity between $F_{1}$ and one of the parental lines. In seed industry, distinguishing the hybrid seeds from the nonhybrid seeds is very important as $F_{1}$ plants growing from hybrid seeds have higher yield potential, resistance to biotic and abiotic stresses as well as genetically and physically more uniform (homogenous) due to phenomenon of heterosis and similar (heterozygous) genetic composition. In 
comparison to morphological and biochemical characterization, DNA based molecular characterization is more useful for ascertaining true genetic relationships among the genotypes.

Molecular markers, such as RAPDs, RFLPs, AFLPs, SSRs and ISSRs have been used in cultivar fingerprinting, seed purity testing and germplasm identification in many crops because they are highly polymorphic, devoid of environmental interactions and represent the genomic constitution of a plant (Rabbani et al., 2010; Zeb et al., 2011; Azam et al., 2013 and Ahmad et al., 2014). Among the various molecular markers systems available, simple sequence repeats (SSRs) or microsatellites are widely accepted and reliable as they are abundant, co-dominant, robust, detect high levels of allelic diversity, easy scoring of the alleles, reproducibility and accessibility to laboratories and can be analysed by a convenient PCR-based method, which makes it easy to screen a large number of individuals (Morgante and Olivieri, 1993; Hancock, 1995 and Paniego et al., 2002).

$F_{1}$ plants contain one copy of genome from both the parents and SSR markers detect alleles of both male and female parents used in cross, thus allowing differentiation of true hybrids from selfed individuals and outcrossed individuals with foreign pollen. Thus, the current study was planned to confirm the hybridity of $F_{1}$ plants using polymorphic SSR markers in Brassica juncea L.

\section{Materials and Methods}

Seeds of two cultivars of Brassica juncea L., namely RSPR-01 (P1) of Indian gene pool, used as female parent and Donskaja-IV (P2) of European gene pool, selected as male parent were raised in pots under field conditions and crossed to develop $F_{1}$ seeds during Rabi 2015-16. F 1 plants (RSPR-01 x
Donskaja-IV) were raised during Rabi 201617 (Fig. 1, 2 and 3). They were subjected to molecular characterization in the Genomics Laboratory, School of Biotechnology, Sher-eKashmir University of Agricultural Sciences \& Technology of Jammu, Chatha.

The genomic DNA was extracted from young seedlings of both parents and progenies using CTAB method (Doyle and Doyle, 1990) with slight modifications; quality of DNA for each sample was assessed on $0.8 \%$ of agarose gel and then stored at $4^{\circ} \mathrm{C}$ for further use. DNA amplification was carried out using twenty SSR primer pairs (Table 1) in polymerase chain reaction (PCR) tubes containing $12 \mu \mathrm{L}$ reaction mixture. The reaction mixture contained $1.5 \mu \mathrm{l}$ of template DNA $(50 \mathrm{ng} / \mu \mathrm{l})$, $1.2 \mu \mathrm{l}$ of $2.5 \mathrm{mM} / \mu \mathrm{l} \mathrm{dNTP}$ (dTTPs, dGTPs, dCTPs, dATPs), $0.5 \mu$ l of each forward and reverse primers, $5 \mathrm{U}$ of Taq polymerase, 1.2 $\mu \mathrm{L}$ of $10 \mathrm{X}$ PCR buffer with $\mathrm{MgCl}_{2}$ (SigmaAldrich). Amplification cycle comprised of initial denaturation for $5 \mathrm{~min}$ at $94{ }^{0} \mathrm{C} ; 30$ cycles of $94{ }^{0} \mathrm{C}$ for $1 \mathrm{~min}$, annealing at $58{ }^{0} \mathrm{C}$ for $1 \mathrm{~min}$ and extension at $72{ }^{0} \mathrm{C}$ for $2 \mathrm{~min}$.; followed by a final extension at $72{ }^{0} \mathrm{C}$ for 7 min. in Master Cycler Gradient (Eppendorf, Germany). The products of amplification were stored at $4{ }^{0} \mathrm{C}$ and resolved by electrophoresis in horizontal agarose gel system at $110 \mathrm{~V}$ for 1 h 30 min. on $2 \%$ agarose gel stained with ethidium bromide $(10 \mathrm{mg} / \mathrm{ml})$ using $1 \mathrm{X}$ TBE buffer. The amplified products were visualized under gel documentation system and the size of amplicons was estimated with the help of 50bp ladder (Fermentas). Genetic polymorphism of SSR markers used in study was recorded on the basis of relative size of bands with 50bp ladder and hybridity confirmation was done by using 100bp ladder.

For analyzing the hybridity of $\mathrm{F}_{1} \mathrm{~s}$, the banding patterns of SSR markers were compared and markers showing polymorphism between parents were identified (Fig. 4). The hybridity 
of $F_{1}$ plants was confirmed when they showed presence of both male and female parent alleles.

\section{Results and Discussion}

\section{Identification of suitable SSR primers}

The good quality genomic DNAs of two Brassica juncea L. cultivars used as parental lines and seven $\mathrm{F}_{1}$ plants without shearing were obtained by modified CTAB extraction method and amplified by a panel of 20 SSR primers. Out of the 20 SSR primers used for screening of parental genotypes, 15 primers were found monomorphic while 5 primers namely BR_A01_13393871, BR_ A03_22221630, BR_A04_9627743, BR_A04_15440685 and BR_A05_25290881 were observed to be polymorphic (Fig. 4) as there was difference in the size of the amplicons obtained after PCR between two parental lines. Suwabe et al., (2002) studied characterization of microsatellites in Brassica rapa L. while Ali et al., (2007) have done molecular characterization of some local and exotic Brassica juncea germplasm for establishing their true genetic status. The markers found polymorphic in this study were used to confirm the hybridity of $F_{1}$ plants. Besides genetic variation, molecular makers have been used for evaluating the genetic stability of crops (Koshy et al., 2013). Pallavi et al., (2011) in sunflower, Liu et al., (2008) in tomato, Dunja et al., (2014) in cabbage identified SSR markers associated with hybridity and genetic purity testing of hybrids. Hipi et al., (2013) showed that SSR markers were more reliable for assessing genetic purity as compared to morphological markers

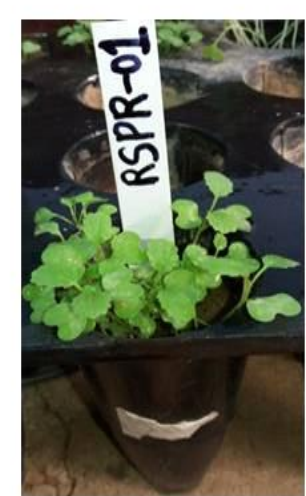

Fig.1 Potted seedlings of P1- RSPR-01

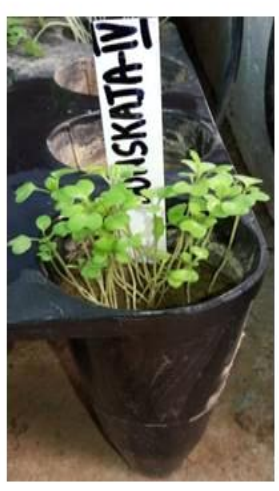

Fig.2 Potted seedlings of P2-DONSKAJA-IV

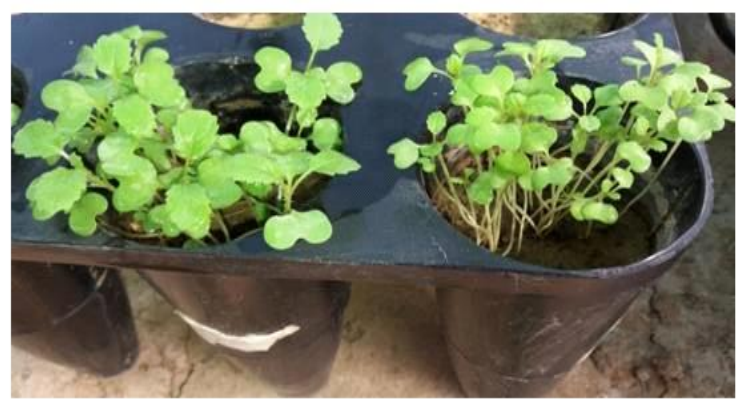

Fig3 Potted seedlings of Hybrid Plants obtained by crossing RSPR-01 x Donskaja-IV (P1xP2) 
Fig.4 Banding pattern of SSR primers with parental genotypes (Primers in red indicate polymorphic primers)
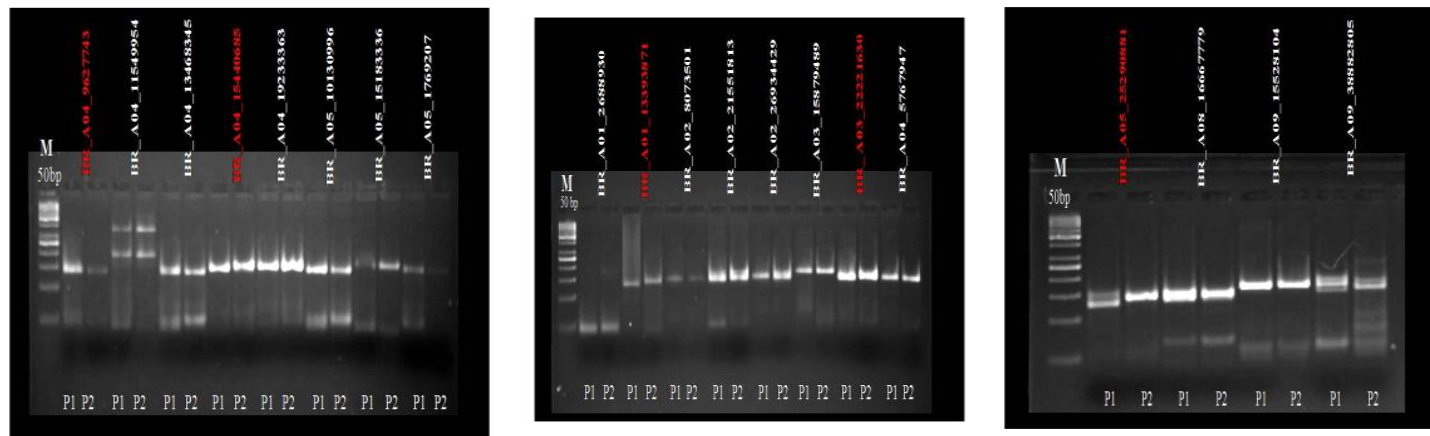

Fig.5 Banding pattern confirming hybridity obtained by primer BR_A01_13393871

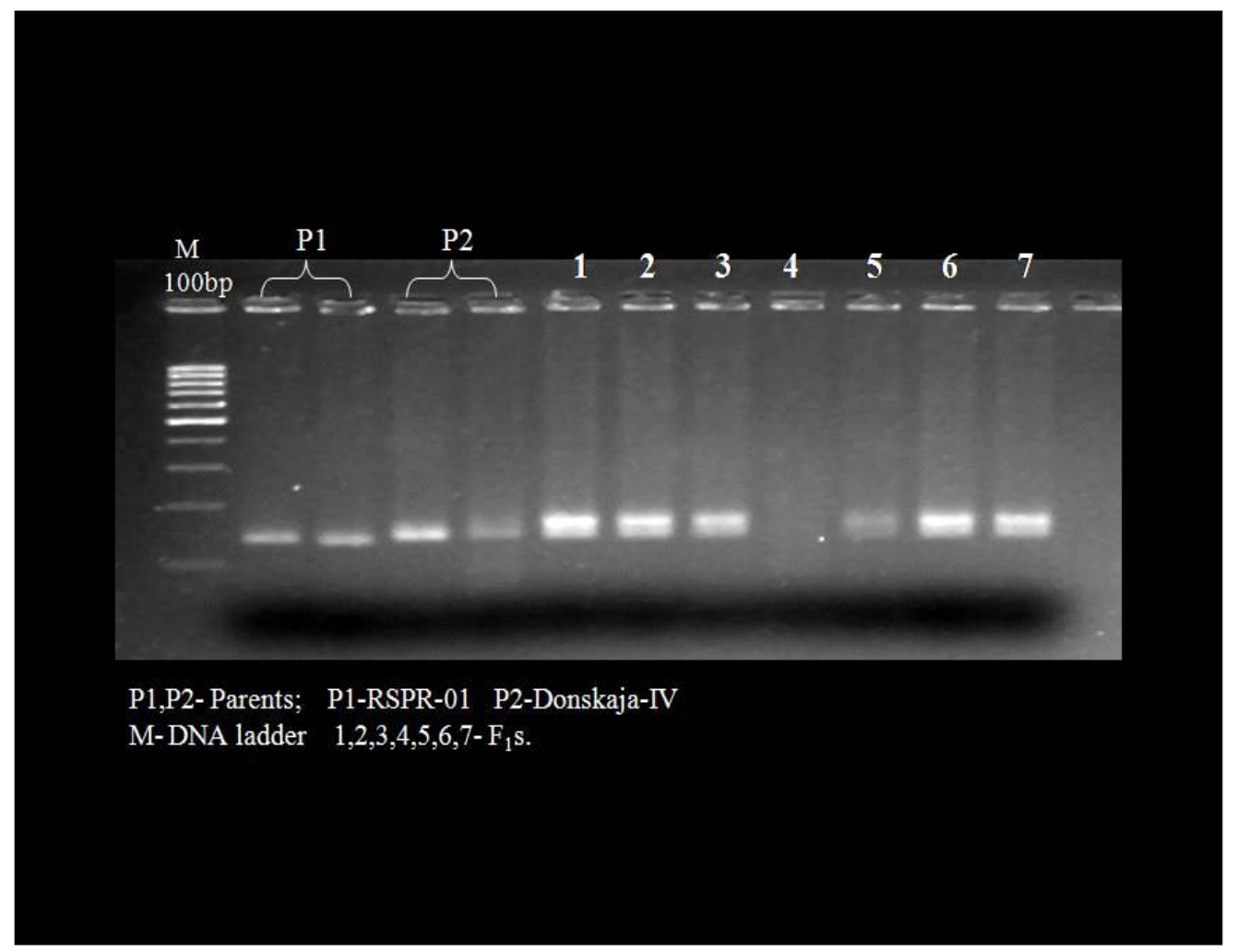


Table.1 List of primers used in the experiment:

\begin{tabular}{|c|c|}
\hline PRIMERS & SEQUENCE 5'-3' \\
\hline 1. BR_A01_2688930 & $\begin{array}{l}\text { Forward: CAATGTAATGGGAAGAAAATG } \\
\text { Reverse: GTACCTCTCCTGGTCCTGTAT }\end{array}$ \\
\hline 2. BR_A01_13393871 & $\begin{array}{l}\text { Forward: CCGTTTTTATGTCACAAATCT } \\
\text { Reverse: AAACAAAACGAACTTTGTCAG }\end{array}$ \\
\hline 3. BR_A02_8073501 & $\begin{array}{l}\text { Forward: CCACCTTTACCAGCACTAAAT } \\
\text { Reverse: TTCTTCAGAGAAGAGAAGAAATG }\end{array}$ \\
\hline 4. BR_A02_21551813 & $\begin{array}{l}\text { Forward: GATCACACTTTTGAACCGTTA } \\
\text { Reverse: TGAGAATGAAGGAGAAGAACA }\end{array}$ \\
\hline 5. BR_A02_26934429 & $\begin{array}{l}\text { Forward: TTGTAGACCTTCTGCTACCAA } \\
\text { Reverse: AAAGACCATACCCTACGAAAT }\end{array}$ \\
\hline 6. BR_A03_15879489 & $\begin{array}{l}\text { Forward: AGTTCAAGGTATTCGCCTAAG } \\
\text { Reverse: TACATCCTCATAGCACTCCTC }\end{array}$ \\
\hline 7. BR_A03_22221630 & $\begin{array}{l}\text { Forward: ATCGTCTCTTTCGTCTTGTCT } \\
\text { Reverse: CGTAAAACTGAAACCATTCAC }\end{array}$ \\
\hline 8. BR_A04_5767947 & $\begin{array}{l}\text { Forward: GACAATGTTCTTGCTATCACC } \\
\text { Reverse: ATAGTTCCTTCGCAACCTATT }\end{array}$ \\
\hline 9. BR_A04_9627743 & $\begin{array}{l}\text { Forward: ATGGAATCTGCTCATCTCAC } \\
\text { Reverse: TAAGCTGCAATGATCAAAGAT }\end{array}$ \\
\hline 10. BR_A04_11549954 & $\begin{array}{l}\text { Forward: CATTTTCCTCCTTGAGATCTAT } \\
\text { Reverse: CTGGTGGAAAACTTGATTTTA }\end{array}$ \\
\hline 11. BR_A04_13468345 & $\begin{array}{l}\text { Forward: CATCACAAGCCAAGAAGAAT } \\
\text { Reverse: AGAGTCTGTGGTTCATCTCCT }\end{array}$ \\
\hline 12. BR_A04_15440685 & $\begin{array}{l}\text { Forward: TTTGAACGATACACAACAACA } \\
\text { Reverse: GTTGGTCCACGAGTAAAAGAT }\end{array}$ \\
\hline 13. BR_A04_19233363 & $\begin{array}{l}\text { Forward: AAAGAAGGGGAAAGTAAACCT } \\
\text { Reverse: GCAACTCTCTTCATTTTCAGA }\end{array}$ \\
\hline 14. BR_A05_10130996 & $\begin{array}{l}\text { Forward: CCTTGTGGTATCGTATTGACT } \\
\text { Reverse: AAAGAATACAACCGCACTGTA }\end{array}$ \\
\hline 15. BR_A05_15183336 & $\begin{array}{l}\text { Forward: GTTGAGCTCTCCTTCACCTAT } \\
\text { Reverse: CGTGCGGGTATTTATTTTTAT }\end{array}$ \\
\hline 16. BR_A05_1769207 & $\begin{array}{l}\text { Forward: ACCCAAATATAGCATCAAGGT } \\
\text { Reverse: ATGTTTGGTATCTGGGTTTGT }\end{array}$ \\
\hline 17. BR_A05_25290881 & $\begin{array}{l}\text { Forward: ATAAAGATTTGATGGGAGGAG } \\
\text { Reverse: GGTGGAGGAGGATAGTTGTAG }\end{array}$ \\
\hline 18. BR_A08_16667779 & $\begin{array}{l}\text { Forward: GAGAGCTTCTTCTGGTTGATAC } \\
\text { Reverse: ACAAAACAGCGAGATCTCTTA }\end{array}$ \\
\hline 19. BR_A09_15528104 & $\begin{array}{l}\text { Forward: GAACAATCTACTGCTGAGTGG } \\
\text { Reverse: CCAAGCTTGCTCCATAGTTA }\end{array}$ \\
\hline 20. BR_A09_38882805 & $\begin{array}{l}\text { Forward: AGTCAGTTTGCAAAGGTATGA } \\
\text { Reverse: ATCTAAGAGAAATCGGGAAAA }\end{array}$ \\
\hline
\end{tabular}




\section{Confirmation of hybridity of $F_{1} s$}

Based on the complementary banding patterns between the hybrid and its parents, the SSR markers BR_A04_9627743 and BR_A01_13393871 were identified as the specific markers which enabled to distinguish and identify hybrid form their parental lines.

In hybrid plants, the SSR marker BR_A04_9627743 amplified two alleles of size 135 and $150 \mathrm{bp}$. The allele of $135 \mathrm{bp}$ was expressed in its female parent (RSPR 01) and allele of size $150 \mathrm{bp}$ was expressed in its male parent (Donskaja-IV). Similarly, in $\mathrm{F}_{1}$ plants the SSR marker BR_A01_13393871 amplified two alleles of size 150 and $140 \mathrm{bp}$. The alleles of $150 \mathrm{bp}$ were expressed in its female parent (RSPR 01) and allele of size $140 \mathrm{bp}$ was expressed in its male parent (Donskaja-IV).

The expression of both the parental alleles in hybrid plants 1, 2, 3, 5, 6 and 7 confirmed their origin from the two parents used in the present study, as well as genuineness of hybrid plants (Fig. 5). Thus, out of seven $F_{1}$ plants, six plants were confirmed as true hybrids on the basis of amplification pattern of SSR marker. Results of the present study are in agreement with the conclusions of Hipi et al., (2013) in maize. The use of SSR markers for genetic purity testing has also been demonstrated in maize (Wang et al., 2002) and in rice (Nandakumar et al., 2004).

This study showed that SSR markers are more reliable and robust for assessing genetic purity as compared to morphological marker. The results of study are expected to be useful in the verification of genetic purity of hybrid seeds in Brassica juncea L. accurately. The study suggests that identification and use of SSR markers can effectively reduce the cost and simplify the procedure of hybridity and purity testing.

\section{References}

Ahmad, R., Farhatullah, Quiros, C. F., Rehman, H., and Swati, Z. A. 2014. Genetic diversity analyses of Brassica napus accessions using SRAP molecular markers. Plant Genet. Resour. 12(1): 14-21 (doi:10.1017/S147926211300021X).

Ali, W., Munir, I., Ahmad, M.A., Muhammad, W., Ahmed, N., Durrishahwar, A.S., and Swati, Z.A. 2007. Molecular characterization of some local and exotic Brassica juncea germplasm. African J. Biotech. 6, 16341638.

Azam, S.M., Farhatullah, Nasim, A., Shah, S., and Iqbal, S. 2013. Correlation studies for some agronomic and quality traits in Brassica napus L. Sarhad J. Agric. 29(4): 547-550.

Doyle, J.J., and Doyle, J.L. 1990. Isolation of plant DNA from fresh tissue. Focus. 12, 13-15.

Hancock, J. M. 1995. The contribution of slippage-like processes to genome evolution. J. Mol. Evol. 41, 1038-1047.

Hipi, A., Surahman, M., Ilyas, S., and Giyanto. 2013. Seed Genetic Purity Assessment of Maize Hybrid Using Microsatellite Markers. International Journal of Applied Science and Technology. 3(5): 66-71.

Koshy, E. P., Alex B. K., and John, P. 2013. Clonal fidelity studies on regenerants of Psophocarpus tetragonolobus (L.) Dc. Using RAPD Markers. The Bioscan. 8(3): 763-766.

Liu, L., Wang, Y., Gong, Y., Zhai, X., Yu, F., and Shen, H. 2008. Genetic Purity Test of F1 Hybrid Tomato Using Molecular Marker Analysis. Acta Horti. 771.

Morgante, M., and Olivieri A.M. 1993. PCRamplified microsatellites as markers in plant genetics. Plant J. 3, 175-182. 
Nandakumar, N., Singh, A. K., Sharma, R. K., Mohapatra, T., Prabhu, K. V., and Zaman, F. U. 2004. Molecular fingerprinting of hybrids and assessment of genetic purity of hybrid seeds in rice using microsatellite markers. Euphytica. 136, 257-264.

Pallavi, H. M., Gowda, R., Vishwanath, K. Y., Shadakshari, G., and Bhanuprakash, K. 2011.Identification of SSR markers for hybridity and seed genetic purity testing in sunflower (Helianthus annuus L.). Seed Science \& Technology. 39 (1): 259-264.

Paniego, N., Echaide, M., Muñoz, M., Fernandez, L., Torales, S., Faccio, P., Fuxan, I., Carrera, M., Zandomeni, R., Suárez, E. Y., and Hopp, H. E. 2002. Microsatellite isolation and characterization in sunflower (Helianthus annuus L.). Genome. 45, 34-43.

Rabbani, M.A., Masood, M. S., Shinwari, Z. K., and Shinozaki, K. Y. 2010.Genetic analysis of basmati and nonbasmati Pakistani rice (Oryza sativa L.) cultivars using microsatellite markers. Pak. J. Bot. 42(4): 2551-2564.

Šamac. Dunja, Bogović, M., Vincek, D., Martinčić, J., and Salopek-Sondi, B. 2014. Assessing the authenticity of the white cabbage (Brassica oleracea var. capitata f. alba) cv. 'Varaždinski' by molecular and phytochemical markers. Food Research International. 60, 266272.

Suwabe, K., Iketani, H., Nunome, T., Kage, T., and Hirai, M. 2002. Isolation and characterization of microsatellites in Brassica rapa L. Theor. Appl. Genet. 104, 1092-1098.

Tautz, D.1989. Hypervariability of simple sequences as a general source for polymorphic DNA markers, nucleic acid research, 17(16): 6463-6471.

Wang, J., Zhong, G. Y., Chin, E. C. L., Register, J. C., Riley, R. D., Nieber, W. S., and Smith, J. S. C. 2002. Identification of parents of F1 hybrids through SSR profiling of maternal and hybrid tissue. Euphytica. 124, 29-34.

Weber, J. L., and May, P. E. 1989. Abundant class of human DNA polymorphisms which can be typed using the polymerase chain reaction. Am. J. Human Genet. 44, 388-396.

Zeb, A., Shinwari Z.K., and Mahmood, T. 2011. Molecular markers assisted genetic characterization of some selected Wild Poaceae species. Pak. J. Bot. 43(5): 2285-2288.

\section{How to cite this article:}

Manmohan Sharma, Dechen Dolkar, R.K. Salgotra, Deepika Sharma, Punya, Amrinder Singh and Gupta, S.K. 2018. Molecular Marker Assisted Confirmation of Hybridity in Indian mustard (Brassica juncea L.). Int.J.Curr.Microbiol.App.Sci. 7(09): 894-900.

doi: https://doi.org/10.20546/ijcmas.2018.709.107 